\title{
The PPP 'without the GP' - a Western Cape story
}

Private GPs in the Western Cape claim they've been side-lined by the provincial health authority in a major new pharmacy-chainfriendly public sector drive to increase the region's overall family planning and infant immunisation footprint.

Instead of simply picking up free supplies of condoms and oral and injectable contraceptives, plus the standard range of infant vaccines from the nearest district hospital or provincial drug supply depot, (as they have in the past), GPs must now tender for a 2-year contract via an exacting 8-page form, and offer free consultations to relevant patients 1 day per week. The Western Cape branch of the South African Medical Association (SAMA), a large SAMA-affiliated GP group, and the 600-member independent practitioner association Cape Primary Care Qualicare (CPC Qualicare) have complained that the initial tender time-frame was too short (extended to 31 January this year), the application process too cumbersome and conditions too demanding and costly for any well-meaning GP.

\section{Clicks 'up and running'}

Provincial health chief Professor Craig Househam put the pharmacyfavouring bias down to economies of scale and 'the cost differential'. Clicks Pharmacies have been distributing and dispensing public sector products and medicines for nearly 3 months in the Cape Metropole via an exclusive 'interim arrangement' that Househam says will be renegotiated based on the longer 2-year contractual obligations. He defended this arrangement, saying Clicks approached the department and 'made the hard yards' in developing it. However, Clicks would have to apply like all others stakeholders for the longer term contracts. 


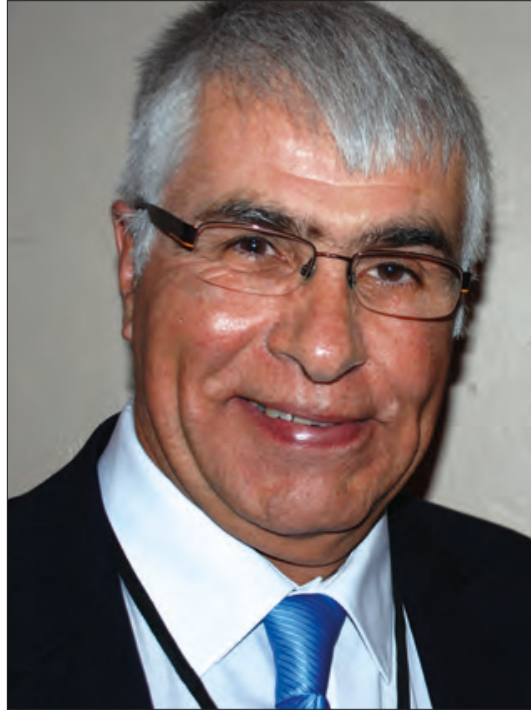

Professor Craig Househam, Western Cape Health Department health chief.

Picture: Chris Bateman.

Househam said the pharmaceutical chain had a strong footprint in the province, excellent cold chain management and storage and distribution capacity that matched his department's ambitious public accessibility goals. The current short-term arrangement with Clicks in the Cape Metro will shortly be extended to its Southern Cape branches. The most frequently used healthcare professionals will be dispensing nurses operating out of pharmacy-chain consulting rooms. The current initial maximum consultation fee is set at R50 for family planning and R75 for infant immunisations. The Clicks services will be free for all patients whose children were born in a state hospital and without access to medical aid (only on Thursday afternoons from $13 \mathrm{~h} 30$ to $17 \mathrm{~h} 00$ - at all other times patients pay the set consultation fees).

\section{Stoltz personally kept a stock list for 20 years, 'but nobody ever asked for it'.}

\section{Province 'squandered opportunity' - GPs \\ However, the GPs believe initial consultation would have enabled a more GP-friendly capitation model, thus protecting their bottom lines while enabling them to help reduce the overall burden of unwanted pregnancies, abortions and disease. Dr Tony Behrman, CEO of CPC Qualicare, said the insistence on a once-weekly free clinic could flood GP practices flooded with public sector}

patients on the day, elbowing out paying clients and reducing an already struggling GP's income. 'What they [Western Cape Health officials] fail to get in selling an argument of "feet through the door" is that there is no huge array of "front-of-shop products" like a Clicks or Dischem in a GP's rooms - plus those chemists aren't in every far-flung town and village like we are.'

$\mathrm{He}$ added, 'Quite honestly, we're very much behind the department in any future joint ventures involving GPs but indicating [as a senior provincial official did at the briefing launch] that those who come on stream will be used as future NHI role models is an unfair carrot to dangle.

While Behrman admits that GP abuse of the previous system was possible (i.e. charging for free supplies), he said most of his members had now simply written off the new public/private partnership system on the grounds of cost and red tape. Dr Marmol Stoltz, chairperson of SAMA's General Private Practice Committee, (GPPC), and chair of Emerging Market Healthcare, a large SAMA-affiliated IPA, said she had offered the services of her latter organisation to Househam at the outset. 'We said we can assist with accountability and the bureaucratic chain network - but we heard nothing subsequently'

Angry that the lack of controls by province was now being used against doctors, she said she personally kept a stock list for 20 years, 'but nobody ever asked for it'. In spite of assurances by Househam to her colleague, Dr Zameer Brey (chairperson of SAMA's Western Cape branch), that GPs on the old network would continue getting stock until the new system began, she has been unable to get supplies for the past year. 'Our groupings are more than

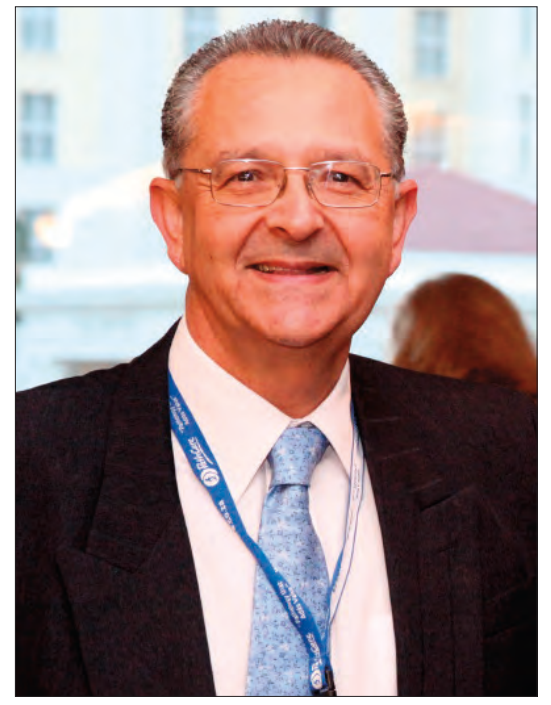

Dr Tony Behrman, CEO of CPC Qualicare. capable of helping them, yet now we're being pilloried and ignored. Clicks seem to have all the current stock; go to a state and family planning clinic and chances are they'll have shortages. How can we be part of an NHI if this is the way we're treated? This was a fantastic opportunity to see if we can make partnerships work. When we challenge them on non-consultation, they infer we're crooks. Nobody once audited me!' she said.

\section{If they [doctors] complain about this they'll have to emigrate before we get an NHI!}

\section{We offered a free 'add-on' service - GP chief}

Brey echoed her sentiments, adding that most GPs did family planning and vaccinations as an 'add-on' free service when a patient came in for an unrelated consultation. 'Do Clicks have 850 access points in the Western Cape? Every one of our GPs could do this ... all of a sudden the access argument for Clicks looks flawed. Many of our members can dispense and understand cold chain management. This whole thing could have been circumvented and was an ideal opportunity for NHI starter pilots - if there'd been real discussion - but they didn't want to.'

Househam said the existing random arrangements (excluding the recent agreement with Clicks) had become irregular in terms of legal requirements governing state products, thus forcing the design of a new distribution protocol and network. This created an opportunity to 'look at who can provide at the cheapest cost'. He explained, 'We have to look at supplies and numbers and the footprint across the province, taking into account viability and realistic distribution. One part of this was regularising the quite haphazard practice of a number of private doctors [Behrman says about 150] in terms of a process that gave them access to state supplies.' Househam emphasised that most patients (i.e. those without medical aid) did not consult private GPs, adding that the probable upshot of the new system was that 'some doctors providing this [service] no longer will and some not providing it may well start'. He had sympathy with the intrinsic costs of running a private practice but intimated that it would be difficult to compete with the economies of scale and efficacy of large pharmaceutical distributors. 


\section{Stiff requirements}

Private sector applicants have to supply a tax and RICA clearance certificate as well as their practice numbers and comply with the updated Medicines Control Act and Nursing Act - all of which Househam said was non-negotiable. However, he was 'fully open' to any GP grouping making a 'cogent and sustainable case in terms of costing - we want to know what will make it viable,' he said.

Izindaba spoke to GPs in Ceres, Wynberg and Sea Point who said that after some 11 years of study, and with major overheads such as the hiring of locums, the consultation fee being offered was untenable. They conservatively estimated the average cost of running a practice at R500 per hour. Said one, 'Clearly we would not expect this [distribution arrangement] on a fee-forservice basis, but some form of capitation: R50 or R75 to last you 3 to 6 months [the average appointment gap for family planning and immunisation consults] until you next see that patient simply won't work.'

Another said that in some up-country provinces, new pilot NHI public/private projects involving GPs were paying R330 per hour. 'This will hardly help them keep their practices open or give them a larger slice of the national pay-out pie, as [health] minister Dr Aaron Motsoaledi indicated' he added caustically.

Another limitation, from a GP perspective, is that the new Western Cape system insists on one distributor per $10 \mathrm{~km}$ radius to enable better management and regulation. 'The game is just not worth the candle,' said one disgruntled GP, who asked what would happen if he turned away a woman suffering deep vein thrombosis as a side effect from taking her family planning medication, adding, 'You'll be on the Health Professions Council carpet so quickly your head would spin'

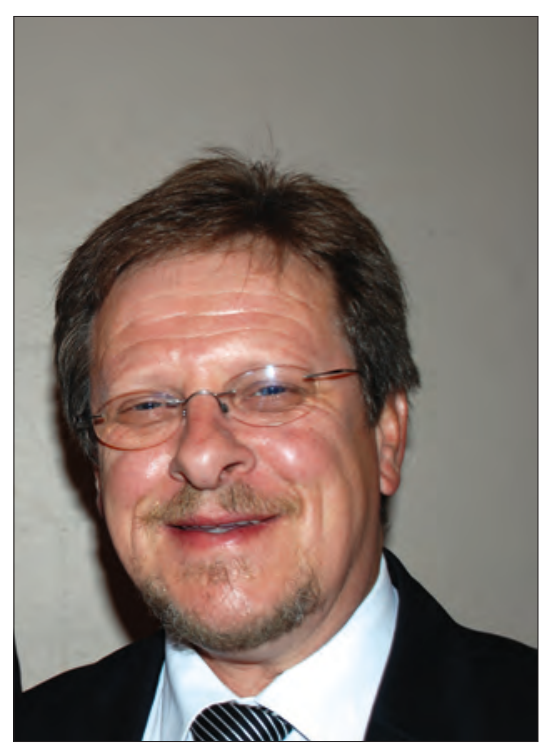

Theuns Botha, Western Cape MEC for Health. Picture: Chris Bateman.

\section{Political health chief'unsympathetic'} Western Cape Health MEC Theuns Botha, a prime mover in the region's increasing public/private initiatives, told Izindaba, 'It's been a free-for-all until now. I don't care whether it's bureaucratic or not - we must have a [data-based] system to enable us to know what we're doing. How are we supposed to efficiently care for 23 million patient visits a year?

After listening more fully to Izindaba's list of GP concerns, he added, 'The only reason chemists are doing it is to get feet in the door. They [doctors] do it for business also. What are they - saints?' He called the new distribution system, 'a mini-mini-mini $\mathrm{NHI}$ ', adding, 'if they [doctors] complain about this they'll have to emigrate before we get an NHI!'

Househam expected the new system to be up and running by June. He said overall immunisation in his province stood at 'between $80 \%$ and $85 \%$ ', a full $10 \%$ short of the desired goal. 'Also, the more we can reduce the number of abortions and unwanted pregnancies, the better. It's been one of our Achilles heels. We've let it off the boil and we're very keen to look at any strategy to push up the numbers accessing preventative services. As for doctors, I really don't think we should exclude good practices that are well-run' he added.

Dr Keith Cloete, Cape Metro District Health Services chief, failed to respond within a week to e-mailed and telephonic requests for contextual data.

How wide the province's door will swing, only time will tell.

\section{Chris Bateman}

chrisb@hmpg.co.za

S Afr Med J 2013;103(3):137-139.

DOI:10.7196/SAMJ.6770 